\title{
Interesting presentation of a retained upper deciduous incisor with apical fenestration
}

\author{
M. B. Edney, ${ }^{1}$
}

\section{A case is described where intrusion of a primary incisor resulting in apical fenestration may have occurred secondary to occlusal forces. The effects on the permanent dentition and possible aetiological factors are discussed.}

$\mathrm{T}$ rauma to the primary incisors is common and is well documented in the literature. The reported incidence ranges from between $4-30 \%$ and is dependent on the sex and age of the child. ${ }^{1}$ The most frequently encountered of these traumatic injuries are subluxation, intrusion and avulsion. Crown and root fractures are rare. $^{2}$ Occasionally trauma can result in apical fenestration, a condition in which the apex of a primary tooth root is found to perforate both the labial alveolus and its overlying gingiva thereby exposing it to the oral environment.

Intrusion with apical fenestration as a result of occlusal forces appears to be less well documented, especially in the primary dentition. A case is reported here, where this appears to have happened. Its presentation and subsequent management are discussed below.

\section{In brief \\ - Although trauma to deciduous incisors is common, apical fenestration as a consequence is rare. \\ - Extraction of the offending tooth is the treatment of choice. \\ - Any resultant malocclusion can then be managed accordingly.}

\footnotetext{
$1^{*}$ General Dental Practitioner, The Dental Centre, 6 The Clockhouse, Brize Norton Road, Carterton, Oxon OX18 3HN

${ }^{*}$ Correspondence to: $M$ Ednay
}

REFEREED PAPER

Received 17.09.99; accepted 13.12.99

(C) British Dental Journal 2000; 188: 369-370

\section{Case report}

A healthy 7-year-old male was referred to the local specialist orthodontic practice by his GDP regarding a retained ULA (61). (upper left first deciduous incisor). This tooth was asymtomatic and there was no history of trauma. Both the dentist and the patient were concerned with its appearance and also the resultant malocclusion: a consequence of its retention.
Fig. 1 Retained deciduous incisor showing apical

Fig. 2 Lateral view retained deciduous incisor fenestration
On examination, it was noted that the patient presented with a Class I molar relationship on a Skeletal I base. Oral hygiene was good and no caries was evident. Although URA (51) had been lost and UR1 (11) was in an acceptable position, ULA (61) was still present; the apex of its root clearly fenestrating through the labial mucosa. As a result of its retention, UL1 (21) had erupted into crossbite with LL1 (31).

Radiographic examination revealed no abnormal pathology, with the root formation of UR1 (11) appearing to progress satisfactorily.

\section{Treatment}

Treatment consisted of extraction of ULA (61), followed by a simple removable
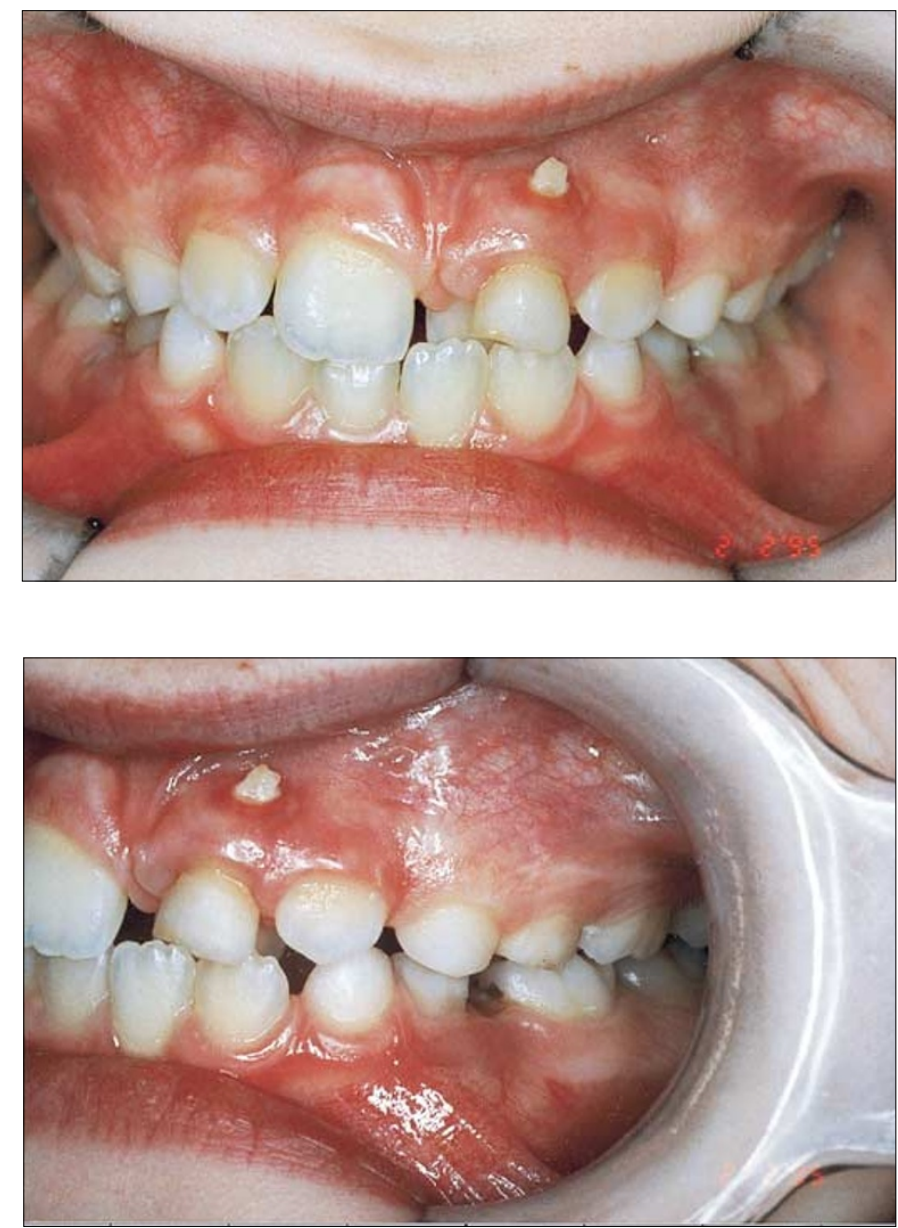
appliance to correct the crossbite. At a review 6 months later, UL1 (21) was still in good position.

\section{Discussion}

A traumatically intruded primary incisor usually requires no immediate treatment as it normally re-erupts within a few weeks and attains its original position within 6 months. $^{3}$

Apical fenestration however appears to require the presence of a non-vital primary tooth which has been affected by caries, trauma or attrition. ${ }^{4,5}$ This loss of vitality, in addition to disrupting its resorption and the consequent eruption of its permanent successor, also creates a periapical infection, which can destroy the labial bone and so extrude the primary root. $^{6}$
In this case however, the apical fenestration associated with ULA (61) does not appear to be traumatic, but secondary to the occlusal forces exerted on it by LL1 (31). As a result of these forces intrusion of ULA (61) has occurred with its apex eventually fenestrating through the thin cortical plate and its overlying mucosa. Subsequently its root has not been resorbed by its permanent successor, and so UL1 (21) has erupted into a palatal position.

\section{Conclusion}

Intrusion of primary incisors secondary to occlusal forces appears to be a rare phenomenon. In addition in this case a lack of apical alveolar bone has resulted in fenestration.
1 Fried I, Erickson P. Anterior tooth trauma in the primary dentition: incidence, classification, treatment methods to sequaelae: a review of literature. ASDC J Dent Child 1995; 62: 256-261.

2 Ravn J J. Sequelae of acute mechanical traumata in the primary dentition. J Dent Child 1968; 35: 281-289.

3 Ravn J J. Development disturbances in permanent teeth after intrusion of their primary predecessors. Scand J Dent Res 1976: 84: 131-134.

4 Menendez O R. Bone fenestration by roots of deciduous teeth. Oral Surg, Oral Med, Oral Path 1967; 24: 654-658.

5 Serrano J. Gingivo-osseous pathological fenestration. Oral Surg, Oral Med, Oral Path 1971; 32: 697-700.

6 Kelly J R, Keeton J M, Barr E S. Apical fenestration. ASDC J Dent Child 1976; 43: 96-98.

\section{BDA Information Centre Services}

\section{Did you know?}

- As a BDA member you can gain access to one of the best dental information services in the world

- You don't have to be based in London to use the service

- You can borrow books, videos and information packages

- You can borrow up to eight items via the postal system The only cost to you is the cost of the return postage. If you're not sure what to request then telephone us and we can advise you.

- You are entitled to free MeduINe searches

Telephone us with a subject and we will send you a list of relevant references with abstracts.

- You can request photocopies of journal articles There is a small charge for this service and you need to fill in a Photocopy Request Form first. Telephone us if you would like one of these forms.

- You can register to receive free Current Dental Titles These are MEDLINE-based lists of references on eight areas of dentistry which are sent to you automatically twice a year. Phone us for a registration form.

For further details of any of these services dial $01719350875 \times 265$. or contact us via e-mail at: Infocentre@bda-dentistry.org.uk Visit the Information Centre web pages at: www.bda-dentistry.org.uk 